\title{
Experimental feasibility study of using date palm oil as a bitumen Bio-Modifier in HMA pavement
}

\author{
Yousef $\mathrm{MA}^{1}$ and $\mathrm{Amin} \mathrm{S}^{2 *}$ \\ ${ }^{1}$ Faculty of Engineering, Environment \& Computing, Coventry University, Priory St, Coventry, West Midlands, CV1 5FB, United Kingdom \\ ${ }^{2}$ Lecturer in Civil Engineering (Highways \& Transportation), Research Associate, Institute for Future Transport and Cities, Faculty of Engineering, Environment \\ \& Computing, Coventry University, Priory St, Coventry, West Midlands, CV1 5FB, United Kingdom
}

\begin{abstract}
This paper examines the effects of Date palm oil as a bitumen modifier on the compressive strength of bitumen and hot mixed asphalt (HMA) pavement. Date palm oil contains anti-oxidant isomers that have the potential to enhance the performance and durability of bitumen. The compressive strength test of asphalt pavement mixed with Date palm oil was performed in accordance with British Standards BS 1881: Part 116: 1983. The cube specimens of asphalt pavement were manufactured mixing with $0 \%, 2.5 \%, 5 \%, 7.5 \%$, and $10 \%$ of Date palm oil out of total sample mass. The experimental results suggested that Date palm oil as a bitumen modifier reduced the compressive strength of HMA pavement. The findings of this paper urge for further experiments to understand the effects of Date palm oil on the asphalt pavements under long-term traffic load, environment and surface drainage.
\end{abstract}

\section{Introduction}

Bitumen is used in hot mixed asphalt (HMA) pavement as a binder of aggregates because of its adhesive properties that reduce the distresses and deformations in asphalt pavement [1]. The performance of bitumen depends on temperature, traffic loads and drainage system. The physical properties of bitumen can be modified and enhanced using additive materials that increase the adhesion with aggregates, increase the elasticity and flexibility of bitumen at low temperature, and reduce the excessive plastic deformation at high temperature [2]. Several studies examined the effect of various additives on bitumen [3-6]. Mashaan et al. [2] used the crumb rubber from scarp tyres to produce high-performance pavement while reducing the environmental impact of waste tyres. Tarefder et al [7] used polymers such as Styrene Butadiene Styrene (SBS) to enhance the grade of bitumen. Some studies used burned waste from palm trees to enhance the performance of bitumen [8].

This paper examines the effects of Date palm oil on the compressive strength of bitumen and HMA pavement. Date palm oil is an edible oil extracted from Elaeis guineensis [9]. The chemistry of palm oil is complicated and primarily comprised of glyceridic and non-glyceridic materials in trace amounts [10]. Date palm oil contains anti-oxidant isomers such as tocotrienol and tocopherol that have the potential to enhance the performance and durability of bitumen [11].

\section{Additive materials for bitumen}

There is a growing importance of modifying bitumen to reduce the pavement distresses under heavy traffic loads, high tyre pressure, and climate change effects (such as frequent fluctuations temperatures and moisture contents). Several studies used waste materials as bitumen modifiers in HMA pavements to prevent the stripping, decelerate the bitumen aging and increase the service life (Table 1) [12-22]. Liquid Anti-Strip (LAS) is the most popular approach that uses the surfaceactive agent to reduce the surface tension and increase the adhesion between bitumen and aggregates and the wettability of aggregates [3]. The selection of effective LAS additives is challenging since there is no selection guidelines concerning the asphalt composition.

Styrene Butadiene Styrene (SBS), a thermoplastic polymer, increases the elasticity, stability, and the stiffness of bitumen. Under high temperature, SBS softens and can be easily mixed with bitumen. [7] investigated the use of $1.5 \%$ SBS in bitumen at a performance grade (PG) level of 64-22 and found that the PG level of bitumen was improved to 70-22. The PG is the method of categorizing the performance of asphalt cement binder at different temperatures. No study examined the effect of SBS on the moisture content of HMA pavement.

The hydrated lime (quicklime) was used to mitigate the moisture susceptibility of bitumen and to improve the resistance of stripping the asphalt mix by 1) increasing the adhesion between bitumen and aggregates; and 2) decreasing the interfacial tension between water and bitumen. The carboxylic acids in the bitumen reacts with hydrated lime forming an insoluble compound that is absorbed by the surface of aggregates [4].

Polyphosphoric Acid (PPA), a mineral liquid polymer that is used as a bitumen modifier to reduce the impact of oxidative aging in bituminous materials. The PPA can be used with other bitumen

*Correspondence to: Shohel Amin, Lecturer in Civil Engineering (Highways \& Transportation), Research Associate, Institute for Future Transport and Cities, Faculty of Engineering, Environment \& Computing, Coventry University, Priory St, Coventry, West Midlands, CV1 5FB, United Kingdom, E-mail: Shohel.Amin@coventry.ac.uk

Key words: compressive strength; bitumen; failure; bitumen modifier; bonding properties; date palm oil

Received: March 16, 2020; Accepted: March 25, 2020; Published: March 29, 2020 
Table 1. Waste materials used as bitumen modifiers in HMA

\begin{tabular}{|c|c|c|c|}
\hline Studies & Additives & Advantages & Disadvantages \\
\hline$[12]$ & crumb rubber & $\begin{array}{c}\text { Increase the softening point, flow properties, strain capacity, } \\
\text { flexibility, and toughness }\end{array}$ & $\begin{array}{l}\text { Decreased the Marshall stability, compressive strength } \\
\text { (when proportion of rubber is more than } 12 \text { percent) }\end{array}$ \\
\hline [13-19] & Plastic & $\begin{array}{l}\text { Increase the softening point, viscosity, Marshall stability, } \\
\text { tensile strength; reduce the deformation and use of bitumen } \\
\text { binder }\end{array}$ & Decrease the penetration, ductility, and flow properties \\
\hline$[20]$ & Rubber and crushed glass & Increase Marshall stability with 10 percent ratio & Stability decreases with lower or higher ratio of 10 percent \\
\hline$[21]$ & Crushed glass & $\begin{array}{l}\text { Decrease the voids in the mineral aggregate (VMA) and } \\
\text { air voids }\end{array}$ & Decrease Marshall stability and tensile strength \\
\hline$[22]$ & Saw dust ash & $\begin{array}{l}\text { Increase the flow properties and durability, and reduce the } \\
\text { cost by } 9.5 \text { percent with } 3 \text { percent ratio of additive }\end{array}$ & $\begin{array}{c}\text { Decrease Marshall stability and strength, and higher } \\
\text { absorption of water in HMA }\end{array}$ \\
\hline
\end{tabular}

modifiers such as, LAS, SBS, and Hydrated Lime. The PPA reacts more efficiently with acidic aggregates such as granite, but it does not react with limestone aggregates. Buncher et al. [5] added 1.25\% PPA in bitumen to increase its PG level from 64-22 to 70-22. Al-Hadidy et al. [6] investigated starch as a bitumen modifier and observed that the penetration of bitumen decreased with the increased content of starch in bitumen at $25^{\circ} \mathrm{C}$ temperature resulting in the improvement of shear resistance of bitumen at medium to high temperature. In addition, the softening point of bitumen was increased with the addition of starch resulting in the increased resistance of permanent deformation in bitumen [6].

\section{Palm Oil - a potential additive material of bitumen}

Palm oil is extracted from the orange-red mesocarp of fruits of palm trees that contains $45 \%$ to $55 \%$ of oil [23]. Palm oil is a mixture of complex triacylglycerols - a basic source of fat molecules of glycerol and fatty acids [24]. In addition, palm oil contains many phytonutrients such as, carotenoids, tocopherols, and tocotrienols [25]. Carotenoid is a compound of 600 fat-soluble pigments that provide the dark orangered color of crude palm oil. Tocols, includes four tocotrienol and four tocopherol isomers and are rich in vitamin $\mathrm{A}$ and vitamin $\mathrm{E}$ that have the potential to enhance the performance and durability of bitumen [11]. Several studies examined the effect of palm oil-based additives on rheological and chemical properties of bitumen $[8,11,26]$. Hainin et al. [8] investigated the effect of Palm Oil Fuel Ash (POFA) on bitumen for different aging conditions. The POFA is comprised of Silicon Dioxide ( $\mathrm{SiO} 2)(53.5 \%)$, Aluminium Oxide (Al2O2) (1.9\%), Ferric Oxide (Fe2O3) (1.1\%), Calcium Oxide $(\mathrm{CaO})(8.3 \%)$, Magnesium Oxide (MgO) (4.1\%) and Sulphur Trioxide (SO3) (2.4\%). The POFA is a byproduct waste material from burning palm kernel shells, palm oil husk and palm oil fiber [8] applied the Rolling Thin-Film Oven (RTFO) and Pressure Aging Vessel (PAV) tests exposing the modified bitumen with increasing temperatures to simulate the aging of bitumen during mixing and placement. Hainin et al. [8] performed the penetration and softening point tests to examine the impact of POFA on the aging characteristics of bitumen and concluded that POFA improved the bitumen's ability to resist ageing due to oxidation.

Rusbintardjo et al. [26] investigated the feasibility of using Oil Palm Fruit Ash (OPFA) as bitumen modifier that is a waste product from the ash of burned mesocarps of palm oil fruits. The OPFA is comprised of $\mathrm{SiO} 2$ (43.6\%), $\mathrm{Al} 2 \mathrm{O} 2$ (11.4\%), $\mathrm{Fe} 2 \mathrm{O} 3$ (4.7\%), $\mathrm{CaO}$ (8.4\%), $\mathrm{MgO}$ (4.8\%), SO3 (2.8\%), and Potasium Oxide (K2) (3.5\%). Rusbintardjo et al. [26] used two sizes of OPFA: 1) Fine-OPFA with a uniform grain size of $75 \mu \mathrm{m}$ and, 2) Coarse-OPFA with maximum grain size of $300 \mu \mathrm{m}$. The main difference between OPFA and POFA is that OPFA contains less $\mathrm{SiO} 2$ that is the main chemical composition of palm oil ashes. Rusbintardjo et al. [26] conducted the penetration, softening point, bending beam rheometer and tension tests to determine the changes in physical properties of bitumen especially the resistance to thermal cracking at low temperatures. The findings from the experiments advocated the use of OPFA as an additive material of bitumen with the improvement of thermal resistance (thermal cracking at $-15^{\circ} \mathrm{C}$, fatigue cracking at $20^{\circ} \mathrm{C}$ and rutting at $70^{\circ} \mathrm{C}$ ) by $70 \%$ and $88 \%$ using fine and coarse OPFA, respectively [26].

Reyes et al. [11] experimented the use of Vitamin E as an antioxidant bitumen modifier since palm oil consists of a large amount of Vitamin $\mathrm{E}$ and other antioxidants. Reyes et al. [11] stabilized Vitamin E of palm oil with fly-ash and hydrated lime since Vitamin E has low viscosity. Reyes et al. [11] found out that Vitamin E reduced the viscosity of bitumen; and the stabilisers (fly-ash and hydrated lime) improved the stiffness of modified bitumen resulting in higher resistance of fatigue cracking but reduction of rutting performance. Reyes et al. [11] agreed that further studies could determine the appropriate proportions of antioxidants and stabilising agents to improve the performance of bitumen. This is obvious a limited number of studies were investigated on palm oil related products as the bitumen modifier mainly focusing on the consistence, suitability, and stiffness and relaxation properties of bituminous material under different climate conditions. Asphalt surface, asphalt binder and base layers of HMA pavements are subjected to compressive stress of dynamic traffic loads, resulting in structural and functional failure. Experiments on the pavement stress-strain behaviour of Date palm oil modified HMA pavement can provide a better understanding on the load response and pavement distress minimisation. This paper investigates the effects of Date palm oil on the stress-stress behaviour of HMA pavement as a bitumen modifier.

\section{Laboratory experiments}

This study performed the compressive strength test of asphalt pavement mixed with Date palm oil in accordance with British Standards BS 1881: Part 116: 1983 [27]. The cube specimens $(10 \mathrm{~cm} \mathrm{x}$ $10 \mathrm{~cm} \times 10 \mathrm{~cm}$ ) of asphalt pavement were manufactured mixing with $0 \%$, $2.5 \%, 5 \%, 7.5 \%$, and $10 \%$ Date palm oil of total sample mass (Table 2 ) (Figure 1a). Each sample (mixed with Date palm oil) was heated in the oven at a temperature of $80^{\circ} \mathrm{C}$ for 1 hour (Figure $1 \mathrm{~b}$ ). The samples were manually compacted in the steel moulds and cured for 1 day (Figure $1 \mathrm{c}$ and $1 \mathrm{~d})$.

\section{Data analysis and discussion}

The compressive strength tests show that asphalt sample without Date palm oil has the highest load resistance $(153.54 \mathrm{~N})$ compared to other samples (Figure 2). The load resistance was decreased to $102.78 \mathrm{~N}$ before the failure for samples with 2.5\% unrefined palm oil (Figure 2). Similarly, the load resistance of modified asphalt pavement was reduced to $27.74 \mathrm{~N}$ and $35.65 \mathrm{~N}$ for $5 \%$ and $7.5 \%$ unrefined palm oil, respectively (Figure 2). The findings of compressive strength tests explain that Date palm oil decreased the viscosity of bitumen. 
Table 2. Proportion of bitumen and date palm oil in each sample cube

\begin{tabular}{|c|c|c|c|c|}
\hline $\begin{array}{c}\text { Sample } \\
\text { No. }\end{array}$ & $\begin{array}{c}\text { Weight of } \\
\text { asphalt sample } \\
\text { (g) }\end{array}$ & $\begin{array}{c}\text { Weight of } \\
\text { bitumen (g) }\end{array}$ & $\begin{array}{c}\text { Percentage } \\
\text { of unrefined } \\
\text { palm oil }\end{array}$ & $\begin{array}{c}\text { Weight of unrefined } \\
\text { palm oil (g) }\end{array}$ \\
\hline 1 & 1962.0 & 98.1 & 0 & 0 \\
\hline 2 & 2100.7 & 105.0 & 2.5 & 3.0 \\
\hline 3 & 1721.0 & 86.1 & 5.0 & 4.3 \\
\hline 4 & 1911.3 & 95.6 & 7.5 & 7.2 \\
\hline 5 & 1823.0 & 91.2 & 10.0 & 9.1 \\
\hline
\end{tabular}

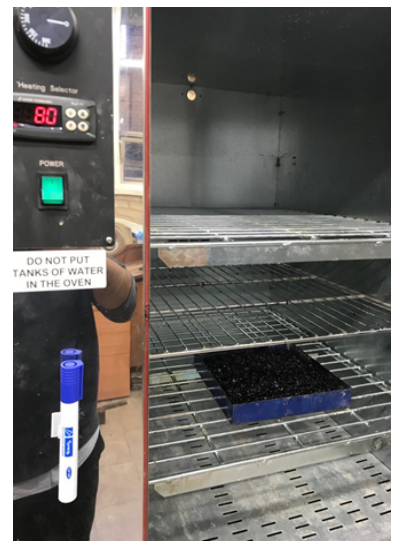

(a) Heating of asphalt mixture and Date palm oil

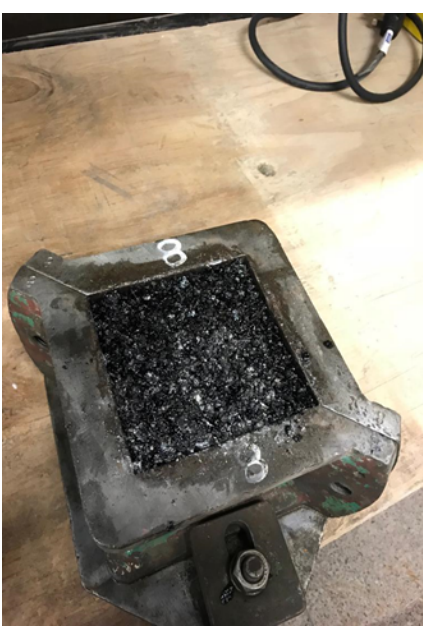

(c) Compaction of mixture

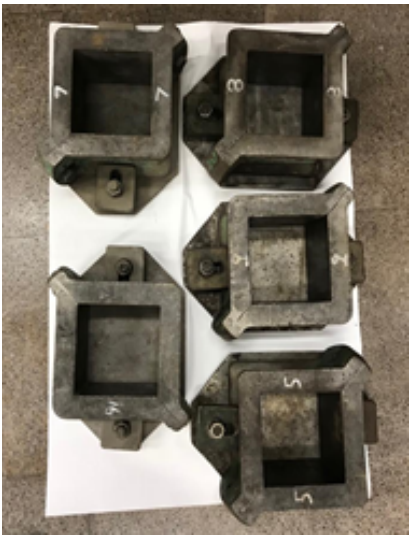

(b) Steel moulds $-10 \mathrm{~cm} \times 10 \mathrm{~cm} \times 10 \mathrm{~cm}$

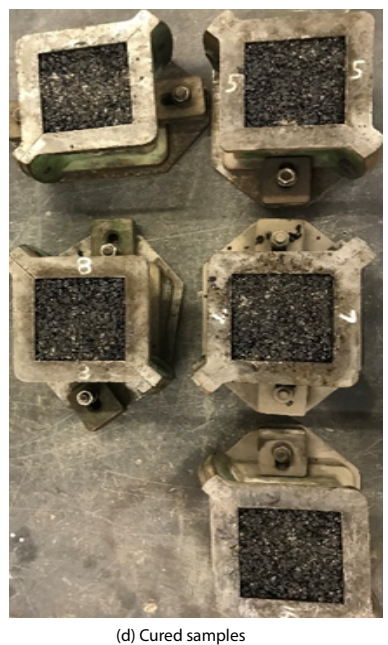

Figure 1. Manufacturing of asphalt specimens for compressive strength test

The experimental results of this study challenge the findings of $[8,11,26]$ who claimed that the addition of palm oil compositions such as POFA, OPFA and Vitamin E enhanced the strength of bitumen and pavement structure. Previous studies mainly focused on the bonding properties and tensile strength of pavement materials; however, the pavement surface layer is subjected to compressive stress under traffic loads. The Date palm oil is futile to resist the compressive stress from traffic loads. In addition, previous studies used dried ash along with palm oil as additives of bitumen that increased the antioxidants or structural integrity.

This study used the solvent based polyurethane to enhance the adhesion of bitumen binder in asphalt specimens. The solvent based polyurethane is the volatile organic compounds (VOCs) and was mixed with bitumen binders in the wet state. The solvent based polyurethane can be cured on air, by heat and under the influence of ultraviolet radiation. This study cured the asphalt mixture on air for one day leaving the polyurethane to form a film. In addition, there was no cross-linking between the polyurethane particles resulting in less bonding properties with bitumen, Palm oil and asphalt mixtures. The compressive strength tests were performed after one-day air curing of asphalt mixtures without exposing the asphalt specimens to long-term effects of weather and traffic loads.

\section{Conclusion}

The HMA pavements subject to fatigue failure and loss of chippings under traffic loads, temperature fluctuations and poor drainage. The additive materials in bitumen enhance the adhesion with aggregates in HMA pavement resulting in increased elasticity and reduced plastic deformation of bitumen under low and high temperatures, respectively. This paper examines the effects of Date palm oil on the compressive strength of bitumen and asphalt pavement. Date palm oil contains anti-oxidant isomers such as, tocotrienol and tocopherol that have the potential to enhance the performance and durability of bitumen. This study performed the compressive strength tests of HMA pavement specimens mixed with Date palm oil in accordance with British Standards BS 1881: Part 116: 1983. The cube specimens $(10 \mathrm{~cm} \mathrm{x} 10 \mathrm{~cm}$ $\mathrm{x} 10 \mathrm{~cm}$ ) of asphalt mixtures were manufactured mixing with $0 \%, 2.5 \%$, $5 \%, 7.5 \%$, and $10 \%$ Date palm oil of total sample mass.

The experiments show that Date palm oil propagates the compressive failure at lower applied loads. For instance, an addition of 2.5\% Date palm oil in the asphalt mixture caused the failure of asphalt specimens at a compression stress that was 33\% lower than that for asphalt mixtures without Date palm oil. The Date palm oil as a bitumen modifier may enhance the bonding properties and tensile strength and reduce the viscosity of bitumen; however, reduces the compressive strength leading the rutting of HMA pavement both at high and low temperatures.

This study used the solvent based polyurethane in the wet state to enhance the adhesion of bitumen binder in asphalt specimens resulting in less bonding between bitumen, Palm oil and aggregates. In addition, the compressive strength tests were performed after one-day air curing of asphalt mixtures without exposing the asphalt specimens to long-term effects of weather and traffic loads. Future studies should manufacture the asphalt mixture with Date palm oil, dry ash and bitumen; air cure the asphalt specimens for long-term period; experiment the pavement distress tests under the long-term effects of traffic load, environment and surface drainage. The binder and asphalt tests are also required to perform on the asphalt mixture with date palm oil to understand the effects on the pavement distresses.

\section{References}

1. Kishchynskyi S, Nagaychuk V, Bezuglyi A (2016) Improving quality and durability of bitumen and asphalt concrete by modification using recycled polyethylene based polymer composition. Procedia Engineering 143: 119-127.

2. Mashaan N, Ali A, Karim M, Abdelaziz M (2014). A review on using crumb rubber in reinforcement of asphalt pavement. The Scientific World Journal 2: 1-21.

3. Guha S, Kumar A (2018) A literature review on anti-strip additives in asphalt mixture International Journal of Science and Research 2.

4. Stuart KD (1990) Moisture damage in asphalt mixtures: A state-of-the-art report McLean, Va, Federal highway administration.

5. Buncher M, D'Angelo JA (2012) Establishing a baseline of knowledge (through 2005) by Reviewing AI IS-220 - Polyphosphoric acid modification of asphalt. Presented at the workshop on polyphosphoric acid modification of asphalt binders, Minneapolis Minnesota, United States, 7-8 April 2009.

6. Al-Hadidy A, Yi-qiu T, Hameed AT (2011) Starch as a modifier for asphal pavingmaterials. Construction and Building Materials 25: 14-20. 
7. Tarefder RA, Zaman AM (2010) Nanoscale evaluation of moisture damage in polymer modified asphalts. Journal of Materials in Civil Engineering 22: 714-725.

8. Hainin M, Jaya RP, Akbar N, Jayanti D (2014) Influence of palm oil fuel ash as a modifier on bitumen to improve aging resistance. Journal of Engineering Research 2: 1 .

9. Siew WL (2002) Palm oil. In: Frank D. G. (ed.) Vegetables oils in food technology composition, Properties and Uses. United Kingdom: Blackwell Publishing.

10. Chong CL (1994) Chemical and physical properties of palm oil and palm kernel oil. In Abdullah(ed.) Selected Readings on Palm Oil and Its Uses. Kuala Lumpur: Palm Oil Research Institute of Malaysia.

11. Reyes C (2012. Influence of anti-oxidant modifications in asphalt binder phesiochemical properties and mixes performance. MSc dissertation, Department of Civil Engineering, The university of Texas at san antonio, San Antonio, TX, USA.

12. Tuncan M, Tuncan A, Cetin A (2003) The use of waste materials in asphalt concrete mixtures. Waste Management and Research 21: 83-92. [Crossref]

13. Appiaha JK, Nana V, Boateng B, Tagbor TA (2017) Use of waste plastic materialsfor road construction in Ghana. Case Studies in Construction Materials 6: 1-7.

14. El-Saikaly MA (2013) Study of the possibility to reuse waste plastic bags as a modifier for asphalt mixtures properties (Binder Course Layer) Gaza: The Islamic University of Gaza

15. Vootukuri VRR (2016) Report on the utilization of waste plastic materials in asphalt pavements. Illinois: Southern Illinois University Carbondale

16. Manju R, Sathya S, Sheema K (2017) Use of plastic waste in bituminous pavement. International Journal of Chem Tech Research 10: 804-811.
17. Ahmadinia E, Zargar M, Karim MR, Abdelaziz M, Shafigh P (2011. Using waste plastic bottles as additive for stone mastic asphalt. Materials and Design 32: 4844-4849.

18. Panyakapo P, Panyakapo M (2008) Reuse of thermosetting plastic waste for lightweight concrete. Waste Management 28: 1581-1588. [Crossref]

19. Hınıslığlu S, Ağar E, (2004) Use of waste high density polyethylene as bitumen modifierin asphalt concrete mix. Materials Letters 58: 267-271.

20. Issa Y (2016) Recycling of waste materials in asphalt mix. Tabuk: Fahd Bin Sultan University

21. Kandhal PS (1992) Waste materials in hot mix asphalt-an overview. National Center for Asphalt Technology 4: 92-6.

22. Yasanthia RGN, Rengarasub TM, Bandara WMKRTW (2016) Study on the performance of waste materials in hot mix asphalt concrete. American Scientific Research Journal for Engineering, Technology and Sciences 23: 252-267.

23. Tan C (2016) Palm Oil: Production, processing, characterization, and uses. Academic Press and AOCS Press 377-391.

24. O’Brien R (1998) Raw materials, in fats and oils: formulating and processing for applications. Lancaster, PA: Technomic Publishing Company, 1 - 46.

25. Basiron Y (2005) Palm Oil. Bailey's Industrial oil and fat products, 333-429.

26. Rusbintardjo G (2013) Fundamental and rheological properties of oil palm fruit ash modified bitumen. Construction and Building Materials 49: 702-711.

27. British Standard (1983) BS 1881-Part 116: Method for determination of compressive strength of concrete cubes.

Copyright: (C2020 Yousef MA. This is an open-access article distributed under the terms of the Creative Commons Attribution License, which permits unrestricted use, distribution, and reproduction in any medium, provided the original author and source are credited. 